\title{
Transvaginal Sacrospinous Ligament Fixation: Revisited in Modern Gynecology
}

\author{
Shraddha S Shastri ${ }^{1}$, Sameer P Darawade ${ }^{2}$, Nikita R Yedage ${ }^{3}$
}

\begin{abstract}
Background: To evaluate intraoperative and postoperative complications and to evaluate recurrence of vault prolapse in women who have undergone unilateral (left) sacrospinous ligament fixation.

Aim: To evaluate safety, effectiveness, and ease of sacrospinous ligament fixation for prevention and treatment of vaginal vault prolapse.

Materials and methods: This study was conducted between January 2016 and October 2017 at Smt. Kashibai Navale Medical College and General Hospital, Pune. This study included 106 patients (out of which18 had vault prolapse and 88 patients had III or IV degree uterine prolapse). Concomitant hysterectomy and sacrospinous ligament fixation were done in 88 patients with uterine prolapse, and patients with vault prolapse underwent sacrospinous ligament fixation. Sacropinous ligament fixation was combined with any other additional procedure if required for that patient.

Results: All complications including intraoperative and postoperative were noted in all patients. One patient had rectal injury ( $n=1 ; 0.94 \%), 1$ patient had abscess $(n=1 ; 0.94 \%), 1$ patient had hemorrhage requiring blood transfusion $(n=1 ; 0.94 \%), 1$ patient had cystocele ( $n=1 ; 0.94 \%)$, 3 patients had urinary tract infection $(n=3 ; 2.8 \%), 16$ patients had postoperative fever $(n=16 ; 15 \%), 21$ patients had postoperative pain $(n=$ $21 ; 20 \%)$, and 2 patients had sciatic neuralgia $(n=2 ; 2.8 \%)$. No recurrence of vault prolapse was noted.

Conclusion: Sacrospinous ligament fixation is a safe, effective, and simple procedure for prevention and treatment of vaginal vault prolapse. Keywords: Pelvic organ prolapse, Transvaginal sacrospinous ligament fixation, Vault prolapse.

Journal of South Asian Federation of Obstetrics and Gynaecology (2020): 10.5005/jp-journals-10006-1782
\end{abstract}

\section{INTRODUCTION}

Pelvic organ prolapse (POP) is a common complaint in women causing varying degrees of discomfort and hampering the quality of life. ${ }^{1,2}$ The lifetime risk of surgery for pelvic prolapse in women is $7 \%$. Clarks et al. found that $12 \%$ undergo second surgery within 6 years, ${ }^{3}$ and Denman et al. found the recurrence rate was $17 \%$ at 10 years. ${ }^{4}$ The ultimate aim of any pelvicorgan prolapse surgery is to reestablish the normal anatomy and minimize the symptoms. MRI determines that the normal position of vaginal apex is approximately $5 \mathrm{~cm}$ inferior to second sacral vertebral body and $5 \mathrm{~cm}$ medial to the ipsilateral spine. Sacrospinous ligament fixation (SSLF) reconstructs this anatomy and suspends the vaginal apex over the levator plate.

Modern gynecologists have concentrated on the various defects in the endopelvic fascia as a cause of POP and attempts at selective treatment for these defects. With the advent of various graft materials like mesh, these procedures started gaining popularity. But owing to recent U.S FDA warnings about mesh-related complications, 5,6 here is an attempt to reconsider the modern role of SSLF, a traditional vaginal procedure in today's era.

Delancey divided the supports of vagina in three levels. The level I defects are apical defects. The sacrospinous ligament suspension seek to restore the level I vaginal support. ${ }^{7}$ Ultimate treatment for the stage III and the stage IV uterine prolapse is considered as the Mayo Wards operation (vaginal hysterectomy). This study is focused to consider sacrospinous ligament fixation simultaneously during the Mayo Wards operation to prevent vault prolapse in future.
${ }^{1-3}$ Department of Obstetrics and Gynaecology, Smt. Kashibai Navale Medical College and General Hospital, Pune, Maharashtra, India

Corresponding Author: Shraddha S Shastri, Department of Obstetrics and Gynaecology, Smt. Kashibai Navale Medical College and General Hospital, Pune, Maharashtra, India, Phone: +91 7507711446, e-mail: drshradds@gmail.com

How to cite this article: Shastri SS, Darawade SP, Yedage NR. Transvaginal Sacrospinous Ligament Fixation: Revisited in Modern Gynecology. J South Asian Feder Obst Gynae 2020;12(3):155-158.

Source of support: Nil

Conflict of interest: None

\section{Materials and Methods}

A total of 106 patients (aged between 40 years and 70 years) were included in our study. The study period was from January 2016 to October 2017. This study is a retrospective observational study carried out at Smt. Kashibai Navale Medical College and General Hospital, Pune. Pelvic organ prolapse quantification (POP-Q) staging was carried out in all patients before the surgery.

\section{Inclusion Criteria}

- Women more than 40 years having pelvic organ prolapse quantification (POP-Q) stage III and IV and vault prolapse after hysterectomy.

(-) The Author(s). 2020 Open Access This article is distributed under the terms of the Creative Commons Attribution 4.0 International License (https://creativecommons. org/licenses/by-nc/4.0/), which permits unrestricted use, distribution, and non-commercial reproduction in any medium, provided you give appropriate credit to the original author(s) and the source, provide a link to the Creative Commons license, and indicate if changes were made. The Creative Commons Public Domain Dedication waiver (http://creativecommons.org/publicdomain/zero/1.0/) applies to the data made available in this article, unless otherwise stated. 


\section{Exclusion Criteria}

- Women more than 40 years having pelvic organ prolapse quantification (POP-Q) stage I and II.

- Women less than 40 years having (POP-Q) stage III and IV.

- Women with serious medical disorder or not fit for anesthesia.

Patients were followed up at 6 weeks and 6 months postoperatively. Patients were analyzed for intraoperative and postoperative complications and recurrence of vault prolapse by doing POP-Q staging postoperatively at an interval of 6 weeks and 6 months.

\section{Operative Technique}

Under spinal anesthesia and in lithotomy position, all the patients were operated. Mayo Wards vaginal hysterectomy was done in patients with stage III and stage IV uterine prolapse, and the repair of anterior wall if required was done. A longitudinal posterior vaginal incision is made and extended up to the apex. The vaginal wall is dissected laterally to expose the pararectal space on the left side. Carrying blunt finger dissection, a window is created between the rectovaginal space and ischial spine. Dissection is done until we reach the ischial spine. The ischial spine as a prominent landmark, the sacrospinous ligament, is palpated and identified medial to it. This sacrospinous ligament is a glistening white structure that originates from the ischial spine and attaches to the lower part of the sacrum.

Now, two Sims speculums are used to retract the vaginal wall and rectum to visualize the sacrospinous ligament. With a 12 inch-long needle holder, the anchoring suture (Prolene No 1 RB) is placed through the sacrospinous ligament starting from the superior border from above downward direction. The suture should be placed $2 \mathrm{~cm}$ medial to the ischial spine so that neurovascular bundle is not injured. When this suture is retrieved, as it is a loop, now it is divided to place two sutures. Thus, two suture pairs are established with one pass. After enterocele repair, sacrospinous sutures are placed through the full thickness of vaginal tissue at the point of new vaginal apex. Vaginal cuff is now sutured and closed. The sutures of sacrospinous ligament are now tied together. This tying of sutures brings the sacrospinous ligament in direct contact with the vaginal epithelium. When healing occurs, vaginal epithelium is fused with the sacrospinous ligament and vault due to fibrosis, and it remains suspended up nicely thereafter. Postoperatively, all the women were given broad-spectrum antibiotic for 5 days (Figs 1 to 7 ).

\section{Results}

In the present study, there were 106 patients, 18 with vault prolapse and 88 patients with III or IV degree uterine prolapse (Tables 1 to 3 ). years).

The average age of the patients was 53 years (range 40-70

Some patients also underwent other procedures.

There were no serious complications of the procedure. Maximum (20\%) number of patients complained of postoperative pain lasting for six weeks. Only one $(0.94 \%)$ patient had rectal injury, one (0.94\%) patient had serious hemorrhage requiring blood transfusion, and one (0.94\%) patient had abscess. None of the patients complained of recurrence of prolapse.

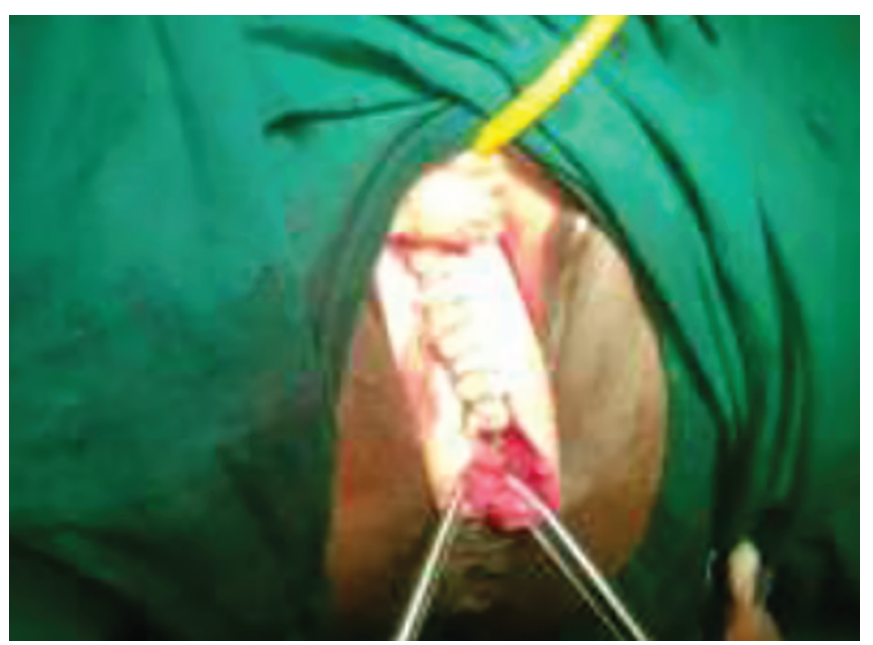

Fig. 1: Intraoperative finding showing vaginal apex outside the level of introitus

\section{Discussion}

The upper third of the vagina (Delancey's biomechanical level I) is suspended from the pelvic walls by vertical fibers of the paracolpium, which is a continuation of the cardinal ligament. The sacrospinous ligament suspension seeks to restore the level I vaginal support. ${ }^{7}$ The true incidence of vaginal vault prolapsed following hysterectomy is approximately $0.5 \% .^{8}$ Numerous techniques for correction of vault prolapsed have been described. ${ }^{9}$ Transvaginal SSLF avoids the potential complications of laparotomy and general anesthesia, resulting in fewer complications and less postoperative pain, decreased blood loss, and greater cost-effectiveness. ${ }^{10}$ As a vaginal procedure, sacrospinous ligament suspension enables concurrent management of anterior and posterior vaginal wall prolapse, which is present in no less than two-thirds of cases with total prolapse. ${ }^{7}$ Sedera ${ }^{11}$ was the first to use the sacrospinous ligament as a secure point of attachment for patients with vaginal vault and uterine prolapse as early as 1958 . Richter ${ }^{12}$ popularized the procedure in Europe in 1968, and by 1971, Randall and Nichols ${ }^{13}$ introduced the technique to the United States. Sacrospinous ligament fixation (SSF) keeps the vaginal axis in the midline and enables adjustment of the vaginal length.

In our study, at 6 weeks of duration, none of the patients had recurrence of prolapse. At the end of follow-up of 6 months, only one patient had recurrence of stage II prolapse according to POP-Q staging and nine had stage I prolapse.

In our study, only one woman had cystocele as recurrence which did not require any surgical intervention. The rates of anatomic failure in published studies vary significantly. Beer and Kuhn reviewed the literature and found that the failure rates ranged from 3 to $37 \% .{ }^{14}$ The disparity in outcome led to a systematic review to explain the differences in failure rates. Failure rates were higher in the anterior compartment repair and lower in the posterior and apical compartments repair. A meta-analysis demonstrates that uterosacral ligament suspension is a highly effective procedure in reestablishing apical vaginal support. A successful anatomic result, defined as support of POP-Q stage 0 ("optimal") or stage I ("satisfactory"), was reported in $98 \%$ of women. All studies, which met the inclusion criteria, were consistent in demonstrating this beneficial effect. ${ }^{15}$ In the present study, only one woman had a mild cystocele recurrence, which did not require any reoperation. Most common 


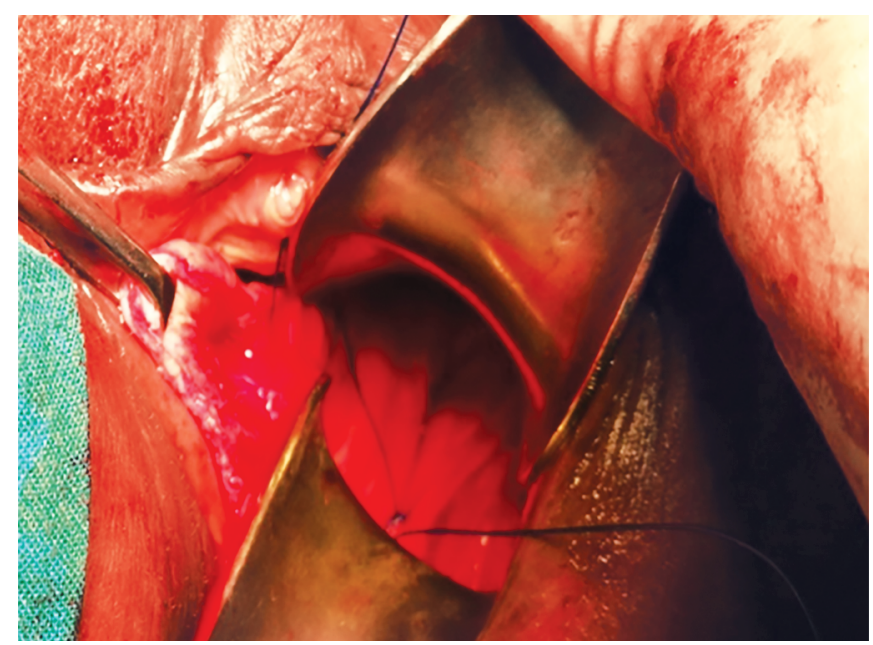

Fig. 2: Using minimal instruments the left-sided sacrospinous ligament identified and permanent suture placed through it

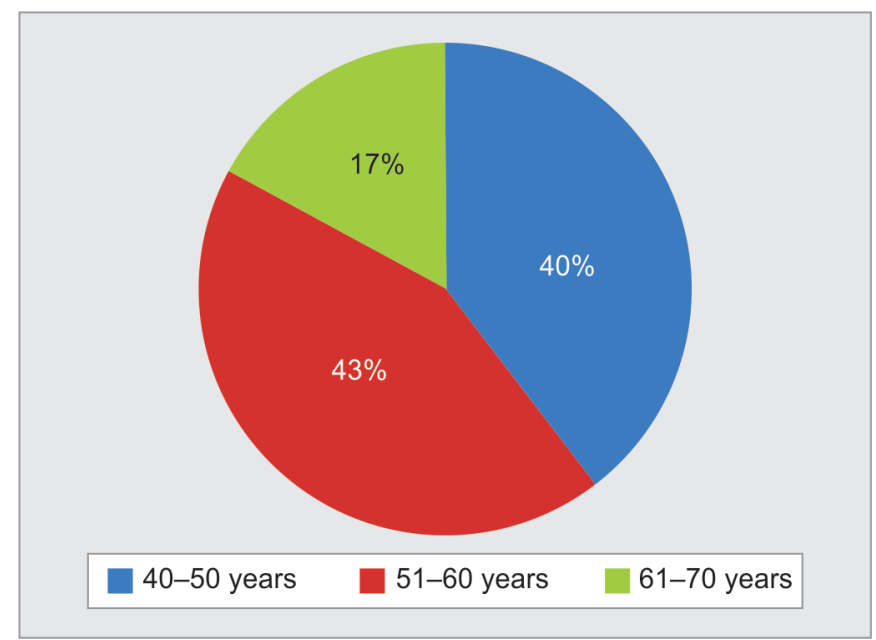

Fig. 4: Distribution of age

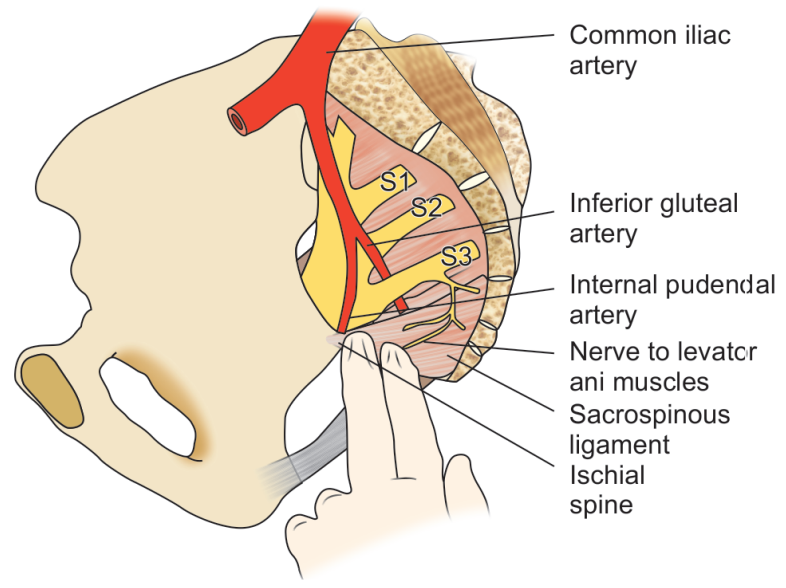

Fig. 6: Anatomy of sacrospinous ligament

complications were postoperative gluteal pain $20 \%$, which lasted for almost 6 weeks. In a study by Nicholas, ${ }^{13}$ damage to the femoral and sciatic nerves were reported in $1.8 \%$, gluteal pain, bladder pain, or unclassified pain in $0.8 \%$, and with the development of vaginal

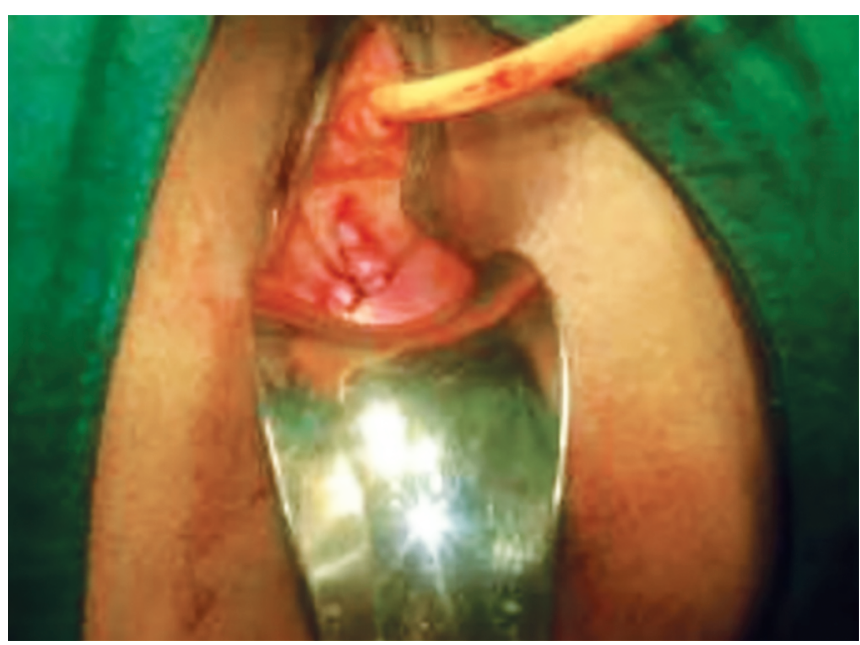

Fig. 3: Finally the sutures placed through the sacrospinous ligament tied to the vault

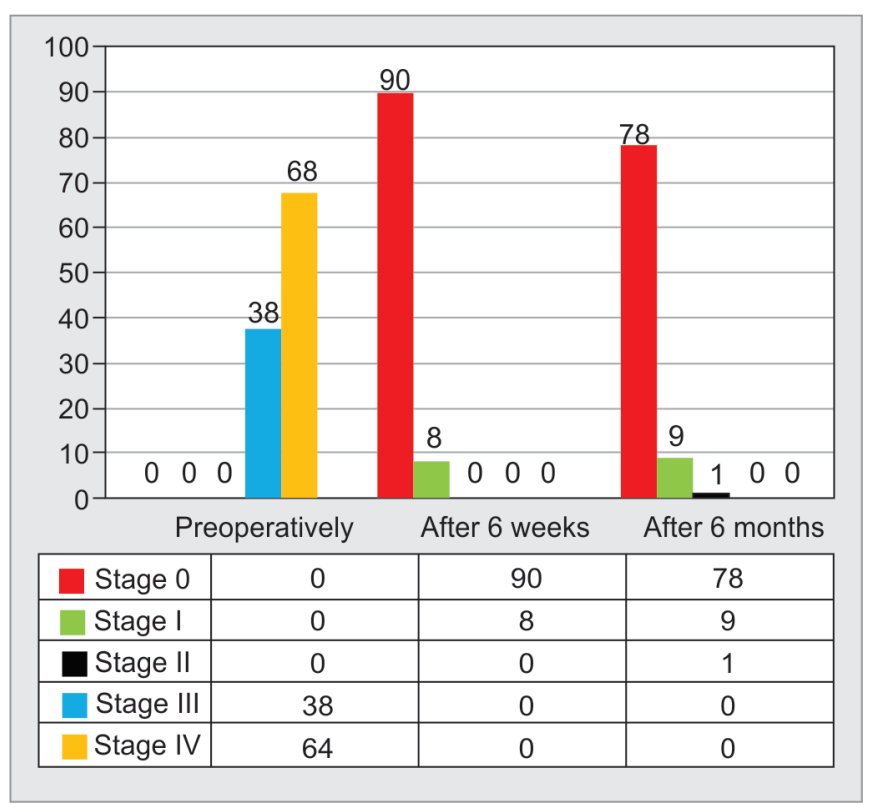

Fig. 5: Showing POP-Q staging preoperatively, after 6 weeks and after 6 months

adhesions or rectovaginal fistula in $0.5 \%$ of patients, respectively. ${ }^{13}$ Sciatic neuralgia was observed in $1.8 \%$ comparable to study by Nicholas. ${ }^{13}$ Febrile morbidity arising due to fever was seen in $15 \%$, abscess $0.94 \%$, and hemorrhage requiring transfusion in $0.94 \%$ of patients. Urinary tract infections occurred in three $(2.8 \%)$ patients which was comparable to the study by Gupta et al. ${ }^{16}$ The urinary tract infections were successfully treated by oral antibiotics. In a study by Pasley, ${ }^{17} 94 \%$ of the patients who underwent sacrospinous suspension for uterovaginal prolapse and vaginal vault prolapse had no persistence or recurrence of vaginal vault prolapse 6-83 months after the procedure. ${ }^{17}$ This is similar to the cases in the present study. In our study, junior residents and assistant professors have done maximum number of cases, with minimum instrumentation (only two Sims speculum) and a mean operative time of 20-25 minutes. Our patients had the lowest complication rates compared to previous studies, which could be due to small sample size. Further studies are required with large sample size. 


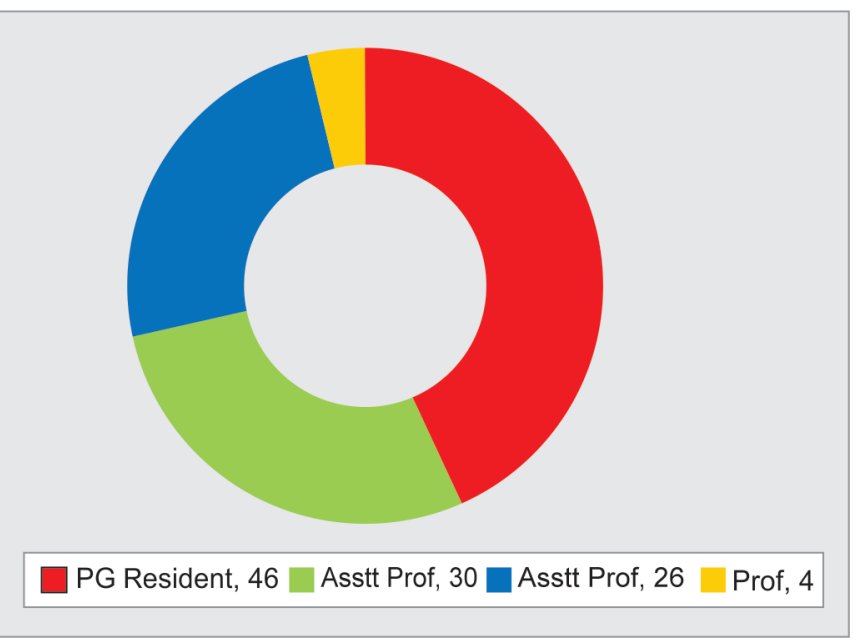

Fig. 7: Ease of operability

Table 1: Types of prolapse (preoperatively)

\begin{tabular}{|c|c|c|}
\hline \multicolumn{2}{|l|}{$P O P-Q$ stage } & No. of patients \\
\hline \multicolumn{2}{|c|}{ POP-Q stage III uterine prolapse } & 32 \\
\hline \multicolumn{2}{|c|}{ POP-Q stage IV uterine prolapse } & 56 \\
\hline \multirow[t]{2}{*}{ Vault prolapse } & POP-Q stage III & 6 \\
\hline & POP-Q stage IV & 12 \\
\hline Total & & 106 \\
\hline
\end{tabular}

\section{ConcLusion}

In conclusion, transvaginal sacrospinous colpopexy is a simple, easy, and safe procedure that can be effectively taught at various teaching organizations and can be performed together with vaginal hysterectomy and vault prolapse.

\section{References}

1. Swift S, Woodman P, O'Boyle A, et al. Pelvic organ support study (POSST): the distribution, clinical definition, and epidemiologic condition of pelvic organ support defects. Am J Obstet Gynecol 2005;192(3):795-806. DOI: 10.1016/j.ajog.2004.10.602.

2. Nygaard I, Barber MD, Burgio KL, et al. Pelvic floor disorders network. Prevalence of symptomatic pelvic floor disorders in US women. JAMA 2008;300(11):1311-1316. DOI: 10.1001/jama.300.11.1311.

3. Olsen AL, Smith VJ, Bergstrom JO, et al. Epidemiology of surgically managed pelvic organ prolapsed and urinary incontinence. Obstet Gynecol 1997;89(4):501-506. DOI: 10.1016/S0029-7844(97) 00058-6.

4. Denman MA, Gregory WT, Boyles SH, et al. Reoperation rate 10 years after surgically managed pelvic organ prolapse and urinary incontinence. Am J Obstet Gynecol 2008;198(5):555.e1-555.e5. DOI: 10.1016/j.ajog.2008.06.049.

5. Abed H, Rahn DD, Lowenstein L, et al. Incidence and management of graft erosion, wound granulation, and dyspareunia following vaginal prolapse repair with graft materials: a systematic review. Systematic review group of the society of gynecologic surgeons. Int Urogynecol J 2011;22(7):789-798. DOI: 10.1007/s00192-011-1384-5.

6. Sung VW, Rogers RG, Schaffer J, et al. Graft use in transvaginal pelvic organ prolapse repair: a systematic review. Society of gynecologic surgeons systematic review group. Obstet Gynecol 2008;112(5):11311142. DOI: 10.1097/AOG.0b013e3181898ba9.
Table 2: Procedures combined with SSLF

\begin{tabular}{lcccc}
\hline & $\begin{array}{l}\text { Vault } \\
\text { prolapse }\end{array}$ & III prolapse & IV prolapse & Total \\
\hline $\begin{array}{l}\text { McCall's } \\
\text { culdoplasty }\end{array}$ & $0(0 \%)$ & $28(87.5 \%)$ & $46(82.1 \%)$ & $88(83 \%)$ \\
$\begin{array}{l}\text { High ligation of } \\
\text { peritoneum }\end{array}$ & $18(100 \%)$ & & & \\
$\begin{array}{l}\text { Anterior } \\
\text { colporrhaphy }\end{array}$ & $16(88.8 \%)$ & $30(93.7 \%)$ & $50(89.2 \%)$ & $96(90.5 \%)$ \\
$\begin{array}{l}\text { Vaginal } \\
\text { hysterectomy }\end{array}$ & $0(0 \%)$ & $32(100 \%)$ & $56(100 \%)$ & $88(83 \%)$ \\
$\begin{array}{l}\text { Posterior colpo- } \\
\text { perineorrhaphy }\end{array}$ & $18(100 \%)$ & $32(100 \%)$ & $56(100 \%)$ & $98(92.4 \%)$ \\
\begin{tabular}{l} 
TOT insertion \\
\hline
\end{tabular} & $1(5.5 \%)$ & $1(3.1 \%)$ & $2(3.5 \%)$ & $4(3.7 \%)$ \\
\hline
\end{tabular}

Table 3: Complications

\begin{tabular}{lcc}
\hline Complication & No. of patients & \% of cases \\
\hline Urinary tract infection & 3 & 2.8 \\
Rectal injury & 1 & 0.94 \\
Abscess & 1 & 0.94 \\
Hemorrhage requiring blood & 1 & 0.94 \\
transfusion & 1 & \\
Cystocele & 0 & 0.94 \\
Recurrent vault prolapse & 16 & 0 \\
Postoperative fever on day & 21 & 15 \\
1 or 2 & 2 & 20 \\
Postoperative pain for 6 weeks & 21.8 \\
Sciatic neuralgia &
\end{tabular}

7. DeLancey JOL. Anatomy of the female pelvis. In: Thompson JD, Rock JA, ed. Te Linde's operative gynecology. 7th ed., Philadelphia: Lippincott; 1992. pp. 33-65

8. Delancey OL. Vaginographic examination of the pelvic floor. Inturogynec J 1994;5:19-24. DOI: 10.1007/BF00451707.

9. Morley GW, Delancey JO. Sacrospinous ligament fixation for eversion of the vagina. Am J Obstet Gynecol 1988;158(4):872-881. DOI: 10.1016/0002-9378(88)90088-9Pubmed pmid: 3364499.

10. Monk BJ, Ramp JL, Montz FJ, et al. Sacrospinous ligament fixation for vaginal vault prolapse: complications and results. J Gynec Surg 1991;7(2):87-92. DOI: 10.1089/gyn.1991.7.87.

11. Sedera L. Surgery in prolapse of a blind-end vagina. Geburtshilfe Frauenheilkd 1958;18(6):824-828.

12. Richter K. The surgical treatment of the prolapsed vaginal fundus after uterine extirpation. A contribution on Amreich's the sacrotuberal vaginal fixation. Geburtshilfe Frauenheilkd 1967;27(10):941-954.

13. Randall CL, Nichols DH. Surgical treatment of vaginal inversion. Obstet Gynecol 1971;38(3):327-332.

14. Beer M, Kuhn A. Surgical techniques for vault prolapse: a review of the literature. Eur J Obstet Gynecol Reprod Biol 2005;119(2):144-155. DOI: 10.1016/j.ejogrb.2004.06.042PubMed PMID: 15808370.

15. Silva WA, Pauls RN, Segal JL, et al. Uterosacral ligament vault suspension: five-year outcomes. Obstet Gynecol 2006;108(2):255-263. DOI: 10.1097/01.AOG.0000224610.83158.23PubMed PMID: 16880293.

16. Gupta P. Transvaginal sacrospinous ligament fixation for pelvic organ prolapse stage III and stage IV uterovaginal and vault prolapse. Iran J Med Sci 2015;40(1):58-62.

17. Pasley WW. Sacrospinous suspension: a local practitioner's experience. Am J Obstet Gynecol 1995;173(2):440-445. DOI: 10.1016/0002-9378(95)90264-3PubMed PMID: 7645619. 